Referencia para citar este artículo: Mansilla, M. A. \& Piñones-Rivera, C. (2017). Lo moreno es bello. Componentes identitarios de las mujeres jóvenes evangélicas aymaras. Revista Latinoamericana de Ciencias Sociales, Niñez y Juventud, 15 (2), pp. 1005-1019. DOI:10.11600/1692715x.1521429082016

\title{
Lo moreno es bello. Componentes identitarios de las mujeres jóvenes evangélicas aymaras*
}

\author{
Miguel ÁNGEL MaNSILLA ** \\ Director de Investigación Universidad Arturo Prat, Chile. \\ CARLOS PIÑONES-RIVERA ${ }^{* * *}$ \\ Investigador Asociado Universidad Arturo Prat, Chile.
}

Artículo recibido en agosto 29 de 2016; artículo aceptado en febrero 28 de 2017 (Eds.)

- Resumen (analítico): en este artículo de investigación cientifica son descritas las concepciones sobre identidad cultural que expresan las jóvenes evangélicas aymaras de la región de Tarapacá en Chile, por medio de las cuales se enfrenta el vacío en el conocimiento sobre los procesos identitarios en poblaciones de jóvenes pentecostales aymaras, que incluyen sistemáticamente distinciones de género. El material forma parte de un estudio mayor que incluyó 25 entrevistas en profundidad a hombres y mujeres aymaras de sectores rurales y urbanos, entre enero y septiembre del 2013. Serán consideradas las entrevistas correspondientes a 8 jóvenes evangélicas estudiantes universitarias de entre 18 y 29 años de edad y se resaltarán tres componentes identitarios significativos: su relación con la masculinidad, la lengua como recurso de identificación, y el territorio como referente identitario. Por último, se concluirá analizando la importancia de la reflexividad sobre los propios supuestos en investigación como factores que invisibilizan los procesos de ciertos grupos sociales.

Palabras clave: identidad cultural, protestantismo, aymara, población indígena, juventud (Tesauro de Ciencias Sociales de la Unesco).

\section{Brown is beautiful. Identity components of young evangelical Christian Aymara women}

- Abstract (analytical): in this article the authors describe the conceptions of cultural identity that are expressed by young evangelical Christian Aymara women from the region of Tarapaca in Chile. There is a gap in the scientific knowledge regarding the identity processes that occur in the Pentecostal Aymara population, including systematic gender distinctions. The material is part of a major study and is based in 25 in-depth interviews with members of the Aymara communities that included men and women from both rural and urban sectors between January and September 2013. The study uses data from interviews with 8 evangelical university students (aged between 18 and 29 years). Three results are highlighted by the authors: their relation with masculinity, language as an identification resource and territory as a modality of identity. Finally, the article analyzes the importance of reflexivity about the researcher's own assumptions in investigation such as factors that obscure the processes of certain social groups.

\footnotetext{
* $\quad$ Este artículo de investigación científica y tecnológica fue elaborado en el marco del proyecto de Fondecyt posdoctorado $\mathrm{N}^{\circ} 3120162$. Nombre investigación: Protestantismo y pentecostalismo aymara en la región de Tarapacá entre 1990-2010. Fecha de inicio: enero de 2012; fecha finalización: octubre de 2014. El mismo corresponde al Área de Sociología y al Subárea de Antropología.

** Sociólogo. Doctor en Antropología (Universidad de Tarapacá). Director de Investigación Instituto de Estudios Internacionales, Universidad Arturo Prat. Orcid: 0000-0001-5684-0787. Correo electrónico: mansilla.miguel@gmail.com

*** Psicólogo. Doctor en Antropología (Universitat Rovira i Virgili). Investigador Asociado Instituto de Estudios Internacionales, Universidad Arturo Prat. Orcid: 0000-0002-4771-3345 Correo electrónico: carlospinonesrivera@gmail.com
} 
Key words: cultural identity, protestantism, aymara, indigenous people, youth (Unesco Social Science Thesaurus).

\section{O escuro é bonito. Componentes identitários das mulheres jovens evangélicas aymaras}

- Resumo (analítico): neste artigo são descritas as concepções da identidade cultural que expressam as jovens evangélicas Aimarás da região de Tarapacá no Chile, por meio das quais são enfrentados o vácuo no conhecimento sobre os processos de identidade em populações de jovens pentecostais aymaras, que sistematicamente incluem distinções de gênero. $O$ material faz parte de um estudo maior, que incluiu 25 entrevistas em profundidade com homens e mulheres aimarás em áreas rurais e urbanas, entre Janeiro e Setembro de 2013. Serão consideradas as entrevistas correspondentes a 8 jovens evangélicas, estudantes universitárias entre 18 e 29 anos idade e destacaram-se três componentes significativos de identidade: a sua relação com a masculinidade, a linguagem como meio de identificação e o território como uma referência de identidade. Finalmente, conclui-se, discutindo a importância da reflexividade sobre as próprias premissas da investigação como factores que fazem invisíveis os processos de determinados grupos sociais.

Palavras-chave: identidade cultural, protestantismo, aymara, população indígena, juventude (Thesaurus de Ciências Sociais da Unesco).

-1. Introducción. -2. El problema de la identidad cultural. -3. La fluidez de identidad. -4. Reflexividad sobre la otredad masculina. -5. La lengua como referente identitario. -6. La territorialidad de la identidad. $\mathbf{- 7 .}$. Conclusiones. -Lista de referencias.

\section{Introducción}

Existen escasas investigaciones sobre
los componentes significativos de la identidad referidos a los jóvenes evangélicos indígenas. Por ejemplo, se han hecho algunas investigaciones entre los grupos indígenas del noreste de Argentina (Ceriani-Cernadas, 2014; Citro, 2005). Pese a la riqueza etnográfica de estos trabajos, la juventud es abordada como una categoría general, sin hacer distinción de género. Sólo al interior de escasos trabajos como el de Ariel Corpus-Flores (2008), se abordan parcialmente las distinciones de género y sus consecuencias prácticas. Las investigaciones sobre evangélicos indígenas en América Latina han dejado de lado a los jóvenes y, especialmente, a las mujeres jóvenes, caracterizándose por ser estudios patriarcales y adultocéntricos.

En Chile pese a que las investigaciones antropológicas sobre pentecostales y mundo indígena lleva unas cuatro décadas para el caso aymara (Mansilla, Muñoz \& Orellana, 2014; Muñoz \& Mansilla, 2015), no encontramos ninguna referencia sobre juventud, pentecostal o protestante, aymara. De igual forma para el mundo mapuche donde las investigaciones se iniciaron a mediados de la década de 1980 (Foerster, 1986, 1989), y se han continuado en los últimos años (Moulian, Oliva \& Toro, 2013; Moulian, 2012), la temática sobre juventud mapuche evangélica está ausente. Los jóvenes evangélicos indígenas (mapuches o aymaras) aún no existen para la antropología de las religiones.

En relación a los trabajos sobre juventud aymara encontramos algunas referencias en Bolivia (Balboa \& Altamirano, 1993), mientras que en Chile, en nuestra área de investigación sólo encontramos un trabajo en el que se "discute algunas ideas en torno a la música sound como dispositivo de producción de identidad entre los jóvenes aymaras del norte grande de Chile, radicado en las ciudades" (Guerrero, 2007, p. 11). Sin embargo, dado sus objetivos, no se hace ninguna distinción de género ni de religión al respecto.

Nuestro objetivo en este artículo es describir las concepciones sobre la identidad cultural que expresan las jóvenes mujeres evangélicas aymaras. Es decir ¿cómo se autoconciben? ¿Cómo relacionan o entretejen sus relaciones identitarias al ser aymara, evangélicas, mujeres 
y jóvenes? Metodológicamente este trabajo se inserta al interior de un proyecto más amplio, en donde se realizaron un total de 26 entrevistas en profundidad a 14 mujeres y 12 hombres de origen aymara, pertenecientes tanto a las zonas rurales como urbanas de la Región de Tarapacá. De esas 26 entrevistas, 11 corresponden a jóvenes entre los 18 a los 29 años, y entre ellas 8 a mujeres, todas estudiantes universitarias de las carreras de psicología, educación parvularia y educación intercultural bilingüe. También hicimos un grupo de discusión y 7 observaciones de campo (colegios, universidad y culto evangélicos). Las entrevistas, grupo de discusión y observaciones de campo, fueron realizadas entre enero y septiembre del 2013.

Entendiendo que la identidad tienen un carácter procesual, construido y nunca acabado (Hall, 2003; Bauman, 2003), y asumiendo su carácter relacional, de historicidad y proyecto (Vergara \& Gundermann-Kröll, 2007), las jóvenes entrevistadas resaltan tres aspectos importantes como parte de su identidad: su relación con la masculinidad (se es mujer en relación con los hombres); la lengua como recurso de transmisión, preservación e identificación étnica; y el territorio como el espacio mítico, histórico y proyectivo de la identidad.

\section{El problema de la identidad cultural}

El concepto de identidad es una de las construcciones modernas más resistentes a la sustitución o al relevo. Hoy en día, cuando proliferan los referentes identitarios con la globalización, cuando las incertidumbres se acrecientan ante todo lo que solía fijar la identidad (familia, comunidad, trabajo, etc.) o cuando aumenta el malestar que los sujetos viven frente a sus identidades asignadas, se hace acuciante reflexionar sobre la identidad. Más aún cuando se ha argumentado que el contexto contemporáneo provoca una complejidad y desestabilización identitaria que "imposibilitan desarrollar un relato de identidad que organice la conducta" (Jiménez, 2011, p. 328).

En este horizonte, las ciencias sociales han debido abandonar los esencialismos de las concepciones tradicionales de la identidad, levantándose varias apuestas teóricas constructivistas caracterizadas por la diversidad, la complejidad y el dinamismo (Garduño, 2003; Levitt, 2007; Chávez-González, 2013). Esto pues como señalan Claros y Viaña, se percibió claramente "la necesidad de trascender un concepto de cultura unitario, es decir, trascender la idea de que la cultura es una entidad que dota homogéneamente de identidad a sus miembros" (Claros \& Viaña, 2009, p. 100).

Dichas apuestas constructivistas sobre la identidad pueden ser situadas en un continuum entre dos posturas extremas: una radical y otra colectivista. En la radical destaca Bauman (1996), para quien la identidad es algo tan flexible que el individuo puede deshacerse de ella cuando quiera. Este carácter evanescente de la identidad no es nuevo, pues los primeros investigadores de la conversión de los aymaras al pentecostalismo aludieron a la fragilidad de la identidad en tiempo de crisis y a que el individuo cambia de una identidad (étnica) por otra (religiosa) por un acto discursivo instrumental (Mansilla et al., 2014; Muñoz \& Mansilla, 2015).

En la postura colectivista, al contrario, encontraríamos a aquellos que consideran a la identidad como una construcción histórica, relacional y proyeccional (Vergara \& Gundermann-Kröll, 2007). Al considerarla a través del triple proceso definido por Berger y Luckmann (2001) de externalización, objetivización e internalización, los colectivistas conciben la identidad centrada en los procesos de internalización y objetivización dando poco lugar a la capacidad resistente, electiva y pragmática del individuo.

Otra aproximación importante es la perspectiva estratégica-posicional de Stuart Hall (2003), según la cual no importa tanto "quiénes somos o de dónde venimos, sino en qué podríamos convertirnos" (Hall, 2003, p. 19). Desde esta concepción los individuos no sólo son portadores de estructuras, sino también "productores de estructuras en los proceso concretos de interacción individual" (Alexander, 1995, pp. 18-19).

Todas estas perspectivas iluminan algún aspecto de la realidad, por lo que en el transcurso de nuestro análisis haremos uso de 
distintas aproximaciones para dar cuenta de la complejidad involucrada.

En lo que sigue revisaremos cuáles serían aquellos elementos que definen hoy los complejos procesos de identidad de las mujeres jóvenes evangélicas y aymaras, centrándonos en su autoconcepción y en las relaciones identitarias que tejen entre su ser joven, aymara y evangélicas.

\section{La fluidez de identidad}

Uno de los temas reiterados por parte de las mujeres jóvenes evangélicas, es la importancia que adquiere el rescate, la conservación y difusión de la cultura Aymara. Consideran que esto es importante, no sólo para los aymaras, sino para toda la región, como un proceso de revalorización e identificación cultural de los propios chilenos con sus raíces culturales. Es decir, que no es sólo una preocupación grupal sino social, ya que se trata de una relación entre identidades regionales e identidades culturales, urbanas y rurales.

Está presente la idea de pensar la identidad desde la relación, no desde la oposición. Como han señalado algunos autores "una identidad cultural no se establece sino en relación a otras identidades" (Vergara \& Gundermann-Kröll, 2007, p. 35). Sin embargo, el carácter relacional de la identidad no supone una relación paritaria; en lo concreto, son los mismos sujetos quienes deciden y acomodan su relación identitaria.

Ésto se puede apreciar cuando las jóvenes entrevistadas supeditan su identidad étnica a su identidad religiosa: "el señor me formó antes de que yo fuera Aymara... indígena, pero antes soy su hija, por eso soy evangélica Aymara" (Mujer, Joven, Entrevista 1, p. 11). Se trata de decisiones condicionadas, no sólo por la religión, sino también por la construcción histórica de lo indígena, con problemas de reconocimiento nacional, estigmatización, negación e invisibilización, al igual que lo ha sido la religión evangélica. Lo indígena frente al estado y lo evangélico frente al catolicismo: dos identidades contrapuestas, pero atravesadas ambas por constantes conflictos y enfrentamientos, como se puede constatar sobre todo en el proceso de conversión. En este contexto, la convivencia de identidades, también resulta compleja y conflictiva para las jóvenes.

Si bien la lógica de priorizar la identidad religiosa es algo común en los discursos pentecostales, no hay que pensar que ésto sea siempre así en la práctica individual. Como se observa, algunos resaltan la pre-existencia étnica, antes que las creencias religiosas:

"de por sí uno ya nace Aymara y el cristianismo se va haciendo con el tiempo. Cuando uno nace, no nace 'al tiro' convertido, va agarrando conciencia, razonando... pero la cultura Aymara es como uno nace siendo Aymara, vive [con] conciencia...vive [con la] cultura. Entonces así es que... primero Aymara y después evangélica" (Mujer, Joven, Entrevista 11, p. 10).

Ésto porque no existe una identidad sino identidades $\mathrm{y}$, por lo tanto, existen jerarquizaciones pero que no son fijas: se trata más bien de flujos de identidades. La identidad, como destacan algunos autores, se vuelve descentralizada, sin fijeza ni permanencia sino fragmentada y compuesta de una variedad de identidades que son contradictorias y no resueltas (Hall, 2003; Alonso, 2005).

Otra joven destaca esta relación:

"Aymara-evangélica...

Aymara porque soy de origen Aymara... estoy aprendiendo [la lengua] Aymara... pero también me identifico porque soy evangélica, porque soy hija de Dios, porque soy cristiana y creo en Dios. Yo soy Aymara y soy evangélica, no haría distinción en ninguna de las dos. O sea no me identifico por ser evangélicaevangélica, evangélica-Aymara, yo soy Aymara y evangélica" (Mujer, Joven, Entrevista 2, p. 16).

Esto sucede porque "la identidad, nunca estará determinada en sí misma, pues estamos atravesados por la otredad" (Marcús, 2011, p. 109).

Una de las entrevistadas da cuenta de la progresiva crisis de identidad cultural por parte de los aymaras, por un proceso constante de urbanización que tiende a ser bastante atrayente por los símbolos de la modernización y el 
desarrollo. Esto genera una valoración por la cultura global en desmedro de la cultura local:

"los jóvenes a lo menos, se están dejando influenciar por la moda... se está perdiendo la identidad cuando están perdiendo el interés por la cultura, y aparte los mismos padres no quieren, a veces, enseñar mucho de su cultura porque igual se discrimina" (Mujer, Joven, Entrevista 11, p. 10).

Aquí constatamos el problema de la falta de reconocimiento, porque "la identidad cultural en cuestión se convierte en un estigma para los propios sujetos que la adscriben y puede ser abandonada por ellos a favor de la identidad cultural hegemónica" (Vergara \& GundermannKröll, 2007, p. 35). Por lo tanto la conciencia de crisis identitaria se trata, también, de lucha, resistencia y conflictos entre identidades. En este sentido, la identidad es una "construcción nunca acabada, abierta a la temporalidad, la contingencia, una posicionalidad relacional sólo temporariamente fijada en el juego de las diferencias" (Arfuch, 2002, p. 24). Es la conciencia de una identidad siempre en crisis, la misma que con matices podemos encontrar entre los evangélicos, los chilenos, etc. La identidad es una constante crisis porque es dinámica y procesual, asequible pero no contenible.

La conciencia identitaria se presenta también como un proceso paradójico y absurdo, cuando son los "otros" quienes resaltan la diferencia subordinada en la indianidad. Se trata de una distinción sustentada en los estereotipos fenotípicos:

"cuando niño a uno sí lo discriminaban, pero pasado el tiempo uno se da cuenta y se empieza a valorar... cuando ya uno tiene identidad, por lo menos, uno puede decir en donde siempre ha estado..." (Mujer, Joven, Entrevista 12, p. 13).

Una identidad religiosa como la evangélica, que no obliga a llevar símbolos explícitos de identificación (por ejemplo el velo islámico o el kipá judío), se puede constituir en una identidad en el silencio para no ser discriminada, pero ¿qué sucede cuando la discriminación pasa por aspectos fenotípicos? Entonces conlleva a transformar la identidad indígena en una vergüenza, una ignominia que afecta a los niños, niñas y jóvenes en el colegio. Esto porque la proyección de una identidad deteriorada conlleva a otras asociaciones: pobreza, estupidez y torpeza, que en la mayoría de los casos van junto a palabras groseras, burlas y metáforas denigrantes.

Este proceso de conciencia identitaria desde la discriminación, de descubrirse inferior a los ojos del otro, genera distintos procesos en el sujeto, dependiendo de variables individuales y sociales. A algunos los conduce a la negación, pero en otros se produce "un retorno a las raíces" (Arfuch, 2002, p. 25). La identidad se constituye en un proceso de "conciencia del estar": es conciencia de espacio y tiempo que los "otros", que te despiertan a esa conciencia, no tienen. Es también un mundo polarizado entre los que "tienen identidad" y los que "no tienen identidad": la identidad es asumida como la conciencia del tiempo y del espacio del ser.

Lafaltadereconocimiento, lasubordinación y la discriminación de la identidad inciden en que algunas jóvenes, influenciadas por sus padres, nieguen su identidad étnica: "Yo soy Aymara, tengo mi certificado (de ser aymara) y todo, pero la verdad es que no, no estoy conectada con mis orígenes étnicos" (Mujer, Joven, Entrevista 21, p. 3).

La identidad tiene también un carácter instrumental y utilitarista. Es decir, la idea que esta joven se preocupe de ser aymara a partir del "certificado indígena", es para obtener beneficios de beca para estudiar:

"Me considero Aymara porque soy Aymara, porque tengo el certificado, pero tener esa identidad me cuesta bastante, porque no sé de baile, no sé palabras, no sé costumbres, no sé absolutamente nada" (Mujer, Joven, Entrevista 21. p. 13).

La identidad étnica "es básicamente un recurso para la movilización [...] dentro de la cual es manipulada para obtener determinados fines" (Bartolomé, 2006, p. 32). Pero esto no es generalizable al grupo: oponerse a una visión primordialista no obliga a entender la identidad étnica como si fuera una pura elección racional ${ }^{1}$. Sí es el resultado de un decurso histórico cuya

Ambas posturas han recibidos fuertes crítica Cfr. (Bartolomé, 2006, p. 30; Río-Ruiz, 2002, pp. 83-88). 
especificidad nos permite entender procesos como el de la negación de la propia identidad ya señalado.

La misma joven destaca que "...yo no me crié en el entorno, por tanto yo no sabía que era Aymara... No tenía conocimiento de la cosmovisión, no tenía conocimiento de la lengua, no tenía conocimiento de nada" (Mujer, Joven, Entrevista 3, p. 3). Esta negación se produce en contextos de fuerte discriminación, en el cual los padres debieron "proteger" a sus hijos de una identidad discriminada, cimentando el deterioro identitario actual.

No obstante, las identidades "emergen en modalidades concretas de juegos de poder y son más el producto de una diferencia y una exclusión que de lo idéntico" (Marcús, 2011, p. 103). Porque en un contexto donde la persona no se siente diferente, no se ve compelido a preguntarse quién es. Y más aún, cuando los padres no conversan de sus raíces para evitar que sus hijos vivan la discriminación que ellos vivieron, se produce una desconexión:

“...la verdad en ese sentido estoy súper desconectada. Y mi papá y mi abuelo eran de Camiña, directo de ahí, se vinieron a la ciudad y una desconexión total, entonces mis papás tampoco conocen nada de eso" (Mujer, Joven, Entrevista 21.p. 4).

Algunos destacan que este instrumentalismo es "una explicación posible para los comportamientos étnicos en ámbitos migratorios urbanos" (Bartolomé, 2006, p. 32). En las ciudades, los padres pueden criar a sus hijos lejos, en el olvido de la identidad étnica, guardando su nostalgia para la privacidad solitaria experimentada cuando no están los hijos:

“...la verdad es que bien desconectada estoy, porque no tengo información sobre las actividades que hacen los compañero aymaras en la U[niversidad]... y es más, el año pasado tuve toda la intención de unirme, el municipio hizo una actividad para poder aprender el idioma y eran sábado, entonces no podía..." (Mujer, Joven, Entrevista 21. p. 12).

Lajoven fue criada por sus padres resaltando su identidad religiosa, pero no la étnica. Siendo evangélica era menos discriminada que ser indígena: "los mismos padres no quieren nunca a veces enseñar mucho de su cultura, porque igual se discrimina" (Mujer, Joven, Entrevista 11, p.10). No obstante, dado que la joven volvió a la región aymara a estudiar, la cultura aymara vuelve a ella. Pese a que dice no tener tiempo, sin embargo la memoria cultural la empuja a ella al retorno de las raíces: "la identidad étnica es una condición a la que se recurre para evaluar los costos y beneficios de la acción social" (Bartolomé, 2006, p. 33).

De igual forma las jóvenes destacan afinidades valóricas entre la identidad evangélica con la identidad aymara. Es una condición que los diferencia de los demás, pero los une con aquellas personas que comparten esos valores. El "ser evangélico no es ser igual a los demás, es obvio, igual que el ser Aymara...te da un tinte, un ámbito en que tú eres distinto al resto" (Mujer, Joven, Entrevista 3, p. 7). Las identidades son distinciones simbólicas y culturales, que pese a que puedan ser discriminadas, no obstante los mismos sujetos le encuentran su valorización.

Ellas declaran como aceptada, por parte de la iglesia, algunas de las prácticas culturales como el baile Aymara, donde no sólo es permitido, sino que también incentivado y potenciado. Al respecto una de la entrevistada destaca "...me acuerdo que las hermanas me pedían que si yo tenía un tiempo para poder enseñar a los niños a bailar...fue diferente verme con mi sombrero, con el mismo traje que era natural, colocarme ojotas" (Mujer, Joven, Entrevista 1, p. 21). Como se aprecia, la identidad cultural, no es sólo un discurso o una narrativa, sino también importa la experiencia de los sujetos. "La pregunta es cómo comprender e interpretar, por ejemplo, la música, los ritos, las festividades religiosas" (Vergara \& Gundermann-Kröll, 2007, p. 50) .

Se resalta también el cuerpo, espacio subjetivo de la materialización de la cultura y la identidad. Algunas jóvenes dicen sentirse orgullosa de la "morenidad". "Tener mis rasgos, mi color de piel, ahora mi lengua es importante y saber que manejaba palabras" (Mujer, Joven, Entrevista 1, p. 11).

Es una revalorización del cuerpo de la mujer aymara, ya que en general "el color 
de la piel más clara es también un signo de belleza" (Gavilán, 2005, p. 144). No obstante estas jóvenes revalorizan su ser morenas como símbolo de belleza, lozanía y autoctonía. "Yo creo que por ser moreno o de otro, o sea de otros rasgos te tachan, que tú eres boliviano, que tú eres así, y no se dan cuenta que los Aymara existimos hace mucho tiempo y que estamos dispersos..." (Mujer, Joven, Entrevista 12, p. 13)". El hecho que por la morenidad la "tachen" de boliviana, resalta también la prexistencia de la etnicidad por sobre la nacionalidad.

Entre las aymaras, "un cuerpo que muestra el trabajo que se ha desarrollado a lo largo de la vida es altamente valorado" (Gavilán, 2005, p. 144). Esa valoración es recuperada por algunas jóvenes: "me siento que valorizo lo que antes no conocía, con respeto y también sentirme orgullosa. Y valorarme, sentirme orgullosa de que etnia soy" (Mujer, Joven, Entrevista 1, p. 21). Así, "se evidencia como un hecho construido socialmente a través de los contactos sociales entre grupos que utilizan los marcadores culturales de manera estratégica y selectiva" (Río-Ruiz, 2002, p. 91).

La identidad es plástica, se deslinda entre identidades étnicas, religiosas, de género, pero también etarias. Fluye y se desliza entre una y otras entre contingencias, espacios y tiempos. Porque la identidad cultural " no se puede referir únicamente al pasado, sino que comprende el presente y una anticipación del futuro" (Vergara \& Gundermann-Kröll, 2007, p. 36):

"Yo creo que como evangélicas tampoco podemos desconocer nuestras tradiciones... [aunque] no participemos directamente, pero uno como Aymara tiene que tener conocimiento" (Mujer, Joven, Entrevista 12, p. 5).

Dado que las identidades que "se construyen en estos grupos son identidades relacionales, ya que necesitan de otras para contrastarse" (Bartolomé, 2006, p. 34), el contexto ayuda a la redefinición y reafirmación identitaria:

"los padres te van vinculando [a las tradiciones] y podríamos decir que yo participé en la enseñanza media en un centro cultural...ahi se reforzaba el tema de identidad y hablaban el tema de discriminación...entonces uno se interesa...era más orgullosa de lo que es" (Mujer, Joven, Entrevista 12, p. 13).

\section{Reflexividad sobre la otredad masculina}

Uno de los referentes identitarios que identificamos es que las jóvenes se preocupan de su identidad de género, que está condicionada por la etnicidad y la religión. En la cultura aymara las categorías hembra-macho y femenino-masculino, son base del pensamiento (Carrasco, 2007; Gavilán, 2005). De igual forma, en la cultura evangélica lo femenino y lo masculino son resaltados como compañerismo y complemento, aun cuando en la realidad los roles y la autoridad masculina siempre están por sobre lo femenino.

Para la cultura aymara "los modelos femeninos y masculinos se elaboran y reelaboran a nivel de las representaciones, considerando la historia oral, adaptándola al contexto y la situación" (Gavilán, 2005, p. 145). Por ello, las jóvenes evangélicas aymaras, siendo consciente que en ambas culturas (étnica y religiosa) se valora el compañerismo y la complementariedad, critican que este discurso no se ha "adaptado a los nuevos contextos y situaciones".

Por ello son críticas de las dos concepciones, porque, pese a que ambas resaltan lo femenino en los mitos y relatos, ellas se sienten discriminadas tanto en las prácticas religiosas como en las étnicas. A pesar de esto, no culpan ni responsabilizan a nadie: sólo resisten y luchan contra el machismo de sus compañeros, porque "varones y mujeres, incorporan las diferencias de género en la ideología sobre la etnicidad, las mujeres resultan siendo tácitamente subordinadas" (De la Cadena, 1992, p. 6).

Las jóvenes son críticas del machismo en general pero con contradicciones, ya que a la vez que critican su presencia entre sus pares, justifican el de sus padres o de los pastores evangélicos. Ahora bien, según las mismas entrevistadas y por variadas razones, aquello estaría disminuyendo. Las jóvenes destacan que el machismo está fundamentalmente alimentado por el alcohol, que después se transforma en violencia. En el caso de la cultura evangélica, no es atrayente el consumo 
de alcohol frecuente en algunas festividades de tradición Aymara. "Ah eso de los hombres que ellos son tan machistas, pero ya no se está viendo eso... el tema del alcohol... que hace que la decencia de los, de lo que en realidad es la cultura se pierda..." (Mujer, joven [26]), Entrevista12, p. 4).

La identidad es un "momento ídentificatorio en un trayecto nunca concluido, donde está en juego tanto la mutación de la temporalidad como la "otredad del sí mismo"' (Marcús, 2011, p. 14). Sin, embargo en relación a las identidades religiosas, el prejuicio recurrente es que junto a la subordinación de la mujeres, ellas mismas se sienten satisfechas o cómodas con tal situación.

Culpan a la víctima de ser víctima, es decir, responsabilizan a la mujer de la reproducción y aceptación del machismo en la religión ${ }^{2}$. Sin embargo acá nos encontramos con jóvenes mujeres lúcidas de tal subordinación al decir: "la religión de por sí es machista. En mi iglesia no hay Pastoras, hay puros hombres [pastores]. Hay mujeres que son dirigentes pero dirigen más bajo. No van a llegar a tomar una iglesia a cargo" (mujer, joven [22], entrevista 11, p. 9). Entre algunos grupos pentecostales, la esposa del pastor recibe el nombre de Pastora, lo que le atribuye un rol de liderazgo religioso. En el caso de algunas jóvenes entrevistadas, a la esposa del pastor se le llamaba "mamá". En otras como la Iglesia Adventista, la esposa del pastor es sólo eso, "la esposa del pastor". El elemento en común de las iglesias evangélicas que están en territorio aymara es que ninguna mujer asume el rol de pastora, es decir el liderazgo formal y visible. Sin embargo algunos autores han destacado que entre las iglesias, en la práctica, la esposa del pastor sí asume un rol de lideresa y pastoral formal. Eso la comunidad lo sabe y lo respeta; lo único que no hace es predicar desde el púlpito (Mansilla \& Orellana, 2014). Empero, la ausencia de acceso a la palabra desde el púlpito y esa negación explicita, formal y sin ambages, es lo que estas jóvenes critican de los evangélicos indígenas.

Según las jóvenes este "machismo" transgrede tanto las creencias tradicionales aymaras de la complementariedad como las

2 Alguno suelen llamarlo femichismo. Al respecto se puede ver Méndez-Cruz (2012). creencias expresadas en la iglesia evangélicas, que resaltan el sacerdocio universal: "lo mismo que la mujer Aymara, yo me he dado cuenta, es un complemento. Una vez que ha pasado el tiempo esos valores se han perdido, el hombre se ha tornado más machista" (mujer, joven [26], entrevista 12, p. 5). Las jóvenes mujeres exigen que los hombres jóvenes aymaras también se adapten a la secularización cultural de la sociedad aymara. Ellas aceptan, valoran y respetan la complementariedad resaltada en la cultura aymara, sobre todo a partir de los mitos, pero en la actualidad lo que concretamente viven es la desigualdad de las mujeres frente a los hombres.

Ellas perciben que actualmente hay más machismo que antes. Esto, porque hoy en día, los hombres jóvenes deberían tener más conciencia, sobre el rol de las mujeres que estudian. Ellas son profesionales, trabajan fuera del hogar, etc. Pero continúan, al igual que antes, con el mismo trabajo doméstico al interior del hogar y su rol como madres: "las mujeres cargan sobre sus espaldas a sus hijos, leña u otros objetos. Los hombres nunca cargarán a los niños, sólo objetos" (Gavilán, 2005, p. 145). Muchas de estas jóvenes estudian, trabajar o visitan a sus familiares en las ciudades de la región de Tarapacá. Tienen acceso a internet, televisión y por lo tanto, exigen que la cultura de la complementariedad se ajuste a los tiempos. Especialmente con la ausencia de violencia "creo que ahora el machismo se ha... se ha ido como a un extremo, al llegar a tal vez creerse superior a alguien o a tratar de llegar a (...) a romper la sana convivencia si no es ya la competencia de poder" (mujer [2], Focus group, entrevista 13, p. 9).

Las jóvenes consideran que el machismo es una característica tanto de los aymaras como de los aymaras evangélicos. Ellas perciben que si bien la cultura y la religión son dinámicas, flexibles y ajustables, en relación a los roles femeninos y masculinos, la cultura presenta más dilación. Este cuestionamiento a las prácticas machistas en la iglesia se expresa de formas más abiertas y directas en las generaciones más jóvenes:

"Eso no me gusta porque igual nosotras la mayoría de la juventud nos miramos 
y ya no son los mismos pensamientos que antes, porque quizás antes más las mujeres se sometían a los hombres y... ahora el mundo ha cambiado" (mujer, joven [25], entrevista 5, p. 8).

Antes las familias que sólo tenían hijas, y no hijos varones, eran considerado una "afrenta cultural":

“mi mamá tuvo tres mujeresy tenía puras mujeres y obviamente la miraban mal, la gente igual la trataba mal, entonces mi papá igual que quería tener un hijo hombre y por lo mismo le pegaba. A la final que (...) Dios que hace grandes cosas...tú le puedes pedir y Dios te lo puede contestar...puede cambiar tu vida, la de tu esposo. Entonces más por eso convirtió mi mamá y entró a la Iglesia evangélica y después mi mamá quedó embarazada de nuevo y tuvo a mi hermano" (mujer, joven [25], entrevista 5, p. 3).

\section{La lengua como referente identitario}

Uno de los aspectos que más conmueve a las jóvenes mujeres entrevistadas es el escaso o nulo dominio de la lengua aymara que poseen. En sus relatos la lengua es puesta en el centro de la cultura y de la identidad étnica y, por lo mismo, la sienten incompleta cuando falta su dominio. Expresan nostalgia por aquellas épocas donde todos dominaban, y no se avergonzaban de usar la lengua aymara. Sin embargo encuentran y valoran pequeños espacios y tiempos, como en los cultos evangélicos, donde se canta en lengua aymara, especialmente entre los pentecostales: "los Pastores hacen culto en Aymara... van a localidades donde están los abuelos... los pastores hablan Aymara, porque si no como van a predicar la palabra de Dios si están hablando otro idioma" (Mujer, joven [20], Entrevista 4, p. 12). Otra de los entrevistadas proveniente de Cariquima, nos explica que "los pastores que también son parte del pueblo Aymara, no siempre hablan esa lengua en todos los rituales" [...] "hablan como intercalado, Aymara y español" (Mujer, joven [25], Entrevista 5, p. 5).

Mayoritariamente la lengua aymara se halla presente en los cánticos e himnos, pero no son todos los cultos evangélicos en esa lengua, pues la mayoría de la población no domina la lengua (Gundermann-Kröll, 1997, 2011) "A veces cantan himnos en Aymara, los coros, pero no, no es que se haga así como toda una reunión en Aymara" (Mujer, joven [25], Entrevista 5, p. $5)$.

\author{
KUNJA JACH'AS TATITUXA (DO) ${ }^{3}$ \\ Dios Awkixay, alaxpach uñtasaxa \\ warawaranakax musphayituw; \\ Kunkamasti thayamp chikaw ist'asi \\ uñjaraktwa intin k'ajatapsa. \\ CORO: \\ Chuymaxasti q'uchuñ munapiniw, \\ ¡Kunja jach 'as Tatituxax! \\ Chuymaxasti q'uchuñ munapiniw \\ ¡Kunja jach’as Tatituxa!
}

Algunos discursos revelan que las predicaciones en Aymara son más frecuentes por parte de quienes integran la comunidad que de los pastores. Se destaca que en Bolivia el uso de las lenguas indígenas está más presentes en los cultos evangélicos. “... en Bolivia vi ahí predican más en Aymara, y también en Quechua" [...] "y no utilizaban mucho el coro que es en español" (Mujer, joven [25], Entrevista 5, p. 6). Esto también resulta de ayuda para el recuerdo de la lengua, ya que los evangélicos aymaras promueven el intercambio de congresos y encuentros de tipo religiosos, sobre todo entre los jóvenes. Según revela una de las entrevistadas, los pastores, de origen aymara, provendrían principalmente de las comunas de Colchane, Camiña y Enquelga (Mujer, joven [20], Entrevista 4. p. 12). Son lugares donde, al parecer, la lengua se practica de manera frecuente por la alta presencia de los abuelos.

Pero los jóvenes, en general, muestran desinterés por el aprendizaje y práctica de la lengua aymara. Se va perdiendo paulatinamente la tradición oral de la lengua por la mayor

3 Señor, mi Dios, al contemplar los cielos/el firmamento y las estrellas mil; /Al oír tu voz en los potentes truenos/ y ver brillar al sol en su cénit. / CORO: Mi corazón entona la canción: / ¡Cuán grande es Él! ¡Cuán grande es Él!/Mi corazón entona la canción: / ¡Cuán grande es Él! ¡Cuán grande es Él! 
influencia y presión urbana de la vida cotidiana (Gundermann-Kröll, 1997, 2011): “... sí cantamos en Aymara pero en realidad como jóvenes poco... se ha perdido un poco la lengua... serán como tres niñas que cantamos en Aymara... los abuelitos si lo cantan en Aymara, pero nosotros no" (Mujer, joven [25], Entrevista 6, p. 9).

No culpan a sus padres por no enseñarles ni motivarlos al aprendizaje de la lengua, al contrario, comprenden la situación ya que ellas mismas experimentaron la discriminación, pero seguramente en menor medida que sus padres:

"Porque lo impuso la sociedad, el Estado, entonces como decía mi abuelito por ejemplo... por la discriminación fue desapareciendo la lengua. Porque él decía que les pegaban si hablaban en Aymara en su tiempo" (Mujer, Joven, Entrevista 7, p. 10).

Este relato se condice, con el rol que cumplió la escuela en la pérdida de la lengua (González, 2002; Gundermann-Kröll, 1997, 2011). Se puede comprender que no sólo existió una discriminación que implicaba rechazo, burla, o distanciamiento, si no que explícitamente se habla de violencia física y simbólica frente al ser aymara, y especialmente hacia quienes hablaban en lengua aymara, considerada como la lengua india y objeto de un sinnúmero de prejuicios racistas que implicó tal expresión.

Uno de los sueños que tienen una de las entrevistadas, es tener un colegio solamente para Aymaras para potenciar la lengua y la cultura aymara. Ella lo justifica "porque se está perdiendo nuestra cultura, yo creo que deberíamos rescatarlo. Porque por ejemplo a mi cuando era niña no me interesaba la lengua, pero ahora yo creo que es importante uno para identificarse saber la lengua" (Mujer, Joven, Entrevista 7, p. 12).

Las entrevistadas destacan, en varias oportunidades, que los cultos evangélicos han ayudado a la mantención de la lengua aymara. Es que "hay Biblia Aymara en nuestra Iglesia por lo menos, hay Biblias traducidas Aymara, hay hermanos que hablan Aymara y como hay personas adultas ya, de edad como se dice hablando Aymara" (Mujer [2]. Focus Group.
Entrevista 13, p. 4). La traducción de la Biblia en idiomas indígenas, se constituyó en uno de los temas más controversiales en la década de 1980, involucrando a antropólogos, intelectuales de izquierda y la Iglesia Católica en contra del $\mathrm{ILV}^{4}$, quienes veían en esta institución la ideología yanqui y la protestantización de los indígenas 5 .

En ocasiones parte de las mismas autoridades de la iglesia son los que ayudan a la sobrevivencia de la lengua Aymara en el tiempo, aunque aquello también se ha ido modificando por cambios generacionales. A una entrevistada se le pregunta sobre los predicadores que utilizan Aymara, donde responde... "cuando hay ancianos pero ellos son, o sea netamente Aymara, saben poco o entienden poco el español. Pero ahora creo que no se ve mucho" (Mujer, Joven, Entrevista 7, p. 7).

Es frecuente identificar en los discursos el gran valor que se tiene por la lengua Aymara, sin embargo cuando a uno de los participantes se les pregunta por qué dejaron de hablar en Aymara en su familia, ella responde que "por lo que he conversado con ellos porque no les permitían o porque se burlaban" (Mujer, Joven, Entrevista 1, p. 11).

Esta burla no sólo se daba en Chile, sino también en Bolivia. Pero los aymaras de Bolivia, a su vez eran discriminado entre los aymaras chilenos: "mi abuelita de parte de mi mamá ella es de Bolivia, entonces ella, mi papá decía de que también se burlaban, la discriminaban porque era de Bolivia" (Mujer, Joven, Entrevista 1, p. 12). También se presenta en los argumentos, que la disminución de la transmisión de la lengua, fue por el temor a que los hijos fueran discriminados, identificando que no es falta de orgullo, respeto o voluntad, si no que finalmente fue un acto que en su origen fue bien intencionado por las presiones de la cultura exógena:

$4 \quad$ Al respecto se puede ver (Marroquín \& Giménez, 1996; Stoll \& Barclay, 1985).

5 Diego Thomson, junto al ex-sacerdote católico Vicente Pazos Kanki (exiliado en Londres en 1817), intentaron traducir el Nuevo Testamento al aymara. La traducción concluyó a fines de 1826. Pero el único texto que lograron publicar fue el Evangelio de Lucas en 1828, y fue el primer evangelio traducido a un idioma vernáculo de América del Sur. No obstante, la traducción del NT fue publicado por primera vez en 1954 y de la Biblia fue publicada por primera vez en 1986. 
"Yo creo que fue por un tema de que antes se les prohibió a ellos de que tal vez pudieron ser sometidos por eso, se hicieron tanta persecución de que ellos no querían que nosotros pasáramos por eso" (Mujer, Joven, Entrevista 12, p. 14).

Uno de los discursos también revela la existencia de autoridades eclesiásticas que también son Aymara, donde se explicó que aquello resulta ser también una manera de integración a la cultura del mismo pueblo:

"Igual hay algunos que son Aymara, como directores de colegios de la zona norte... en Camiña hay un pastor que es Aymara que dirige todos los pueblos... Aymara o mapuches los mandan a su zona, porque ellos saben tratarlos... la gente Aymara va a tener mayor recepción a esas personas" (Mujer, Joven, Entrevista 11, p. 11).

Por otro lado existe una modificación en los parámetros educacionales por parte de los integrantes más jóvenes, que hace crítica sobre las maneras que en fueron educados, al desatender la importancia de las costumbres Aymara. Si bien pudo haber sido justificado por la discriminación, hoy el interés por el rescate de lo étnico es más valorado... "Yo no haría, lo que hizo mi mamá conmigo... porque no sé hablar Aymara, pero si yo hablo Aymara yo le voy a enseñar a mi hijo... para que no se pierda la identidad del idioma" (Mujer, Joven, Entrevista 11, p. 13).

Nos encontramos con conversaciones que revelan las motivaciones por estudiar Pedagogía de Educación Básica Intercultural Bilingüe, donde nos explica que a través de contactos de cercanos, gustos por la lengua y la pedagogía, hicieron que finalmente optara por esta carrera universitaria:

"un amigo me contó de esta carrera que se estaba dando, dije -ya es pedagogía, sí, ya hay beca, ya y tiene que ver con la lengua-yo no sé hablar, -ah que interesante ya me gustaría hablar, aprender hablar mi lengua" (Mujer, Joven, Entrevista 2, p. 4).

Por ello para las jóvenes, "recuperar la lengua, es fundamental" (Mujer, Joven,
Entrevista 4, p. 6). Se repite la necesidad de valorar la lengua repetidamente en las conversaciones, destacando como uno de los aspectos más importantes. "la lengua, porque creo que con eso uno se identifica como Aymara" (Mujer, Joven, Entrevista 7, p. 5).

El interés por aprender la lengua Aymara implica reconocer su relevancia como un catalizador de relaciones familiares y culturales: "no tan sólo la lengua por hablarla sino que involucra aspectos familiares, involucra la misma vida, involucra uno sentirse orgulloso, orgullosa de quién es y tomar conciencia" (Mujer, joven [28], entrevista 1, p. 12).

Es decir, que el acto de aprender y practicar la lengua Aymara implica más que la lengua en sí, implica de hecho la expresión de una identidad que los diferencia con otros pueblos.

\section{La territorialidad de la identidad}

Las jóvenes destacan, tanto en la cultura aymara como la evangélica, la existencia y el realce del sentido de gratitud y respeto por la naturaleza. Para los aymara la tierra es la Pachamama, para los evangélicos la tierra es creación de Dios.

Una joven resalta sobre una ritualidad aymara:

"los hermanos Aymara, iban cantando... y lograba ver... el respeto que le tenían... yo igual los respetaba y a la vez descansaba y miraba a mi alrededor y daba gracias a la creación que la hizo tan hermosa" (En la subida al cerro de Cariquima) (Mujer, joven [28], Entrevista 1, p. 16).

La misma entrevistada, también acentúa sobre el uso de la coca como recurso salutífero, a lo que responde: "Sí, cuando tengo problemas de estómago en ese momento me ofrecieron y recuerdo que igual comí" (Mujer, joven [28], entrevista 1, p. 16).

En momentos de urbanización de la cultura aymara, debido a la constante migración rural urbana, se ha generado un profundo despoblamiento de los antiguos pueblos aymaras. Sin embargo: "la tierra es todo" (Mujer, joven [25], Entrevista 5, p. 20). Los 
pueblos, cada vez más son habitados sólo por abuelos: "Nosotros sin la tierra no somos nada, todo está complementado... los occidentales no valoran la tierra" (Mujer, joven [25], Entrevista 5, p. 20). Esto porque los aymaras "participan de masivas migraciones y una parte de ellos se proletariza en los centros urbanos regionales, pero mantienen actividades agropecuarias $\mathrm{o}$ relacionadas (comercio y transporte agrícola regional), lo que les otorga continuidad con su pasado de campesinos andinos" (Gundermann Kröll \& Cortez, 2008, p. 106).

Como han planteado Magno, Doula y Pinto "la construcción de la identidad de la juventud rural está constantemente influenciada por el universo urbano; esta confluencia se debe a las nuevas experiencias espaciales y comunicacionales que vivenciamos actualmente, colocando 'el tránsito' entre lo rural y lo urbano como un proceso constante" (Magno, Doula \& Pinto 2011, p. 307).

En el discurso de varios de los entrevistados, se repite de manera frecuente el vínculo con la tierra, destacándose un aprecio por ser el medio que brinda los sustentos, y que es también parte de un respeto heredado por las tradiciones ancestrales.

"La tierra está, está, está como el sustento, el sustento, la sustentabilidad para la vida, de ahí sacamos los productos, el sustento de los animales, el sustento de los animales nosotros" (Mujer, Joven, Entrevista 2, p. 10).

El despoblamiento del altiplano Aymara y el envejecimiento de la población generan una nostalgia de la tierra por parte de las jóvenes: "creemos en la tierra, en todo, todo lo que gira alrededor de nosotros, o sea, nosotros no somos superiores a ellos sino que todos nos complementamos entre sí. Esa es mi perspectiva a diferencia del mundo occidental" (Mujer, Joven, Entrevista 6, p. 1).

No es una desterritorialización, sólo urbanización, ya que también ha sido históricamente espacio de movilidad aymara. No obstante es un des-anclaje de la cultura respecto de la tierra.

Una de las opiniones vertidas en las entrevistas, en oposición a algunas declaraciones y en concordancia con otras, da cuenta de una sincronía valórica entre el ser Aymara y el ser evangélico, afirmando que no son excluyentes, y es más, complementario... "No creo que sea excluyente una de otra...yo encuentro que el ser Aymara encuentro como el equilibrio del hombre con la naturaleza. Entonces...eso le ayuda a una en la formación de hombre con la relación con el otro."(Mujer, Joven, Entrevista 3 , p. 4). La misma entrevistada declara haber participado en una de las ceremonias donde se le pide a la naturaleza, la posibilidad de seguir trabajando otro año en ella...

"me acuerdo que la profesora [...] hizo una ceremonia de la phawa y yo para mí eso era nuevo. Y es como, es una actividad en donde se pide permiso a la tierra, a la Pachamama y la bendición para comenzar este nuevo proceso" (Mujer, Joven, Entrevista 3, p. 4).

"El hombre no indígena va la naturaleza como un elemento...la tierra se puede explotar, sacarle todo el provecho posible" (Mujer, Joven, Entrevista 3, p. $5)$.

"Lo que tiene la cultura Aymara, es que todo...tiene vida, todo tiene un equilibrio...Por ejemplo en el tema de la quinoa, yo voy a ocupar la tierra durante un determinado tiempo y después hay que dejarla descansar ... todo es cíclico" (Mujer, Joven, Entrevista 3, p. 5).

Se hace hincapié en la división del trabajo, donde cada integrante cumple una función... "la cosmovisión porque creo que todos en esta tierra cumplimos una función, no hay una que, que sea más que una planta, porque eso también aporta oxígeno...todos tenemos como una función" (Mujer, Joven, Entrevista 7, p. 5).

\section{Conclusiones}

El estudio de las concepciones sobre identidad cultural expresadas por las jóvenes mujeres evangélicas aymaras nos ha permitido constatar la importancia de una teorización sobre la identidad que no suponga elementos primordiales ni su dependencia de rasgos estables. Siendo fieles al material expuesto, la identidad se nos presenta más bien como el 
juego de articulación de múltiples identidades, en un proceso fluido, descentralizado, sin fijeza ni permanencia, fragmentario y compuesto por elementos contradictorios e irresolubles.

No obstante lo anterior, hemos podido identificar tres temáticas recurrentes en nuestro material que organizan y sintetizan los contenidos empíricos: la reflexividad sobre la alteridad masculina, la centralidad de la lengua, la territorialidad. Estos tres elementos funcionan como nodos en cuyo paso recurrente se van tejiendo y estabilizando los flujos de la identidad de las jóvenes pentecostales aymaras de la región de Tarapacá.

Ahora bien, al pensar las relaciones entre las tres dimensiones identitarias aquí desarrolladas (ser aymara, evangélica y mujer joven), podemos ver que existe una tensión relativa entre las dos primeras. Mientras ciertos elementos de la identidad aymara son combatidos por la religiosidad evangélica, sobre todo aquellos concebidos como idolátricos (Piñones-Rivera, Mansilla \& Muñoz, 2016), otros son potenciados o incluso reivindicados por dicha relación.

El mejor ejemplo es el de la lengua aymara como referente identitario. Desde la vertiente étnica la lengua aymara es valorizada como soporte de la cosmovisión, como reservorio de lógicas culturales diversas cuya alteridad es profunda, pues responde incluso a gramáticas distintas (Guzmán de Rojas, 1985; Hardman, Vásquez \& Yapita, 2001). Desde la vertiente evangélica el sentido es distinto, más bien como un medio para la evangelización, dando cuenta de un sentido utilitario-instrumental, en el cual lo priorizado es la difusión de la palabra cristiana y no la preservación de la cosmovisión. Dicha tensión no se descubre cuando se analiza la posición de la mujer. Podríamos decir que la aparente oposición entre ambos referentes culturales se resuelve en la confluencia respecto de la posición subordinada de la mujer. Esta complejidad de tensiones y confluencias nos permite advertir los desvíos que introduce cualquier pensamiento polarizado o unilateral sobre la identidad.

Creemos que es importante continuar profundizando en el estudio de los procesos identitarios entre mujeres jóvenes pentecostales aymaras, contrarrestando el vacío significativo existente en el conocimiento. Es importante continuar investigando en estos procesos con otro tipo de actores, pues nos parece muy probable que las coordenadas que organizan el flujo identitario aquí presentado y analizado, sean característicos de grupos que han accedido a la educación superior y participado de procesos educativos que enfatizan dichos tópicos (género, lengua $\mathrm{y}$ territorio) como parte del actual y dilatado proceso chileno de replanteamiento de la relación del Estado con los pueblos originarios, fortalecido desde la ratificación del Convenio 169.

Pensamos que dicha profundización debe hacerse desde una posición reflexiva sobre cómo las tendencias adultocéntricas, patriarcales, neocoloniales y hegemónicas en lo religioso, aún continúan definiendo la agenda de investigación en las ciencias sociales, invisibilizando la realidad de grupos sociales históricamente subordinados como el aquí presentado, por su pertenencia a pueblos originarios, por su condición de género, por su segmentación etaria y por su subalternización religiosa.

De otra manera, en el plano académico continuaremos contribuyendo con el proceso histórico aquí mostrado de identidades avergonzadas, negadas y desconectadas al cual estas jóvenes mujeres han debido hacer frente.

\section{Lista de referencias}

Alexander, J. C. (1995). Las teorías sociológicas desde la Segunda Guerra Mundial. Barcelona: Gedisa.

Alonso, B. (2005). El juego de las diferencias. Lecturas sobre identidad $y$ cultura. Recuperado de: http:// webiigg.sociales.uba.ar/iigg/jovenes investigadores/3 Jornadas Jovenes/ Templates/Eje\%20identidad-alteridad/ alonso-identidad.pdf.

Arfuch, L. (2002). Problemáticas de la identidad. En L. Arfuch (comp.) Identidades, sujetos y subjetividades, (pp. 19-41). Buenos Aires: Prometeo.

Balboa, A. \& Altamirano, J. (1993). La identidad en la juventud aymara-urbana 
alteña. Temas Sociales, (17), pp. 121-129.

Bartolomé, M. A. (2006). Los laberintos de la identidad. Procesos identitarios en las poblaciones indígenas. Avá, (13), pp. 1-19.

Bauman, Z. (1996). De peregrino a turista, o una breve historia de la identidad. En S. Hall \& P. du Gay (eds.) Cuestiones de identidad cultural, (pp. 40-68). Buenos Aires: Amorrortu.

Bauman, Z. (2003). Comunidad. En busca de seguridad en un mundo hostil. Buenos Aires: Siglo XXI.

Carrasco, A. M. (2007). Influencias de la ideología religiosa en las significaciones de la sexualidad en mujeres aymaras del norte de Chile. Cultura y Religión, 27 (1), pp. 24-47.

Ceriani-Cernadas, C. (2014). Configuraciones de poder en el campo evangélico indígena del Chaco argentino. Sociedad y Religión, 24 (41), pp. 13-41.

Chávez-González, M. L. (2013). La familia, las relaciones afectivas y la identidad étnica entre indígenas migrantes urbanos en San Luis Potosí. Relaciones (Zamora), 34 (134), pp. 131-155.

Citro, S. (2005). Ritual y espectáculo en la música indígena: el caso de los jóvenes toba del chaco argentino. Latin American Music Review, 26 (2), pp. 318-346. Doi: 10.1353/lat.2006.0004.

Claros, L. \& Viaña, J. (2009). Lainterculturalidad como lucha contrahegemónica. Fundamentos no relativistas para una crítica de la superculturalidad. En J. Viaña, L. Claros, J. Estermann, R. FornetBetancourt, F. Garcés, V. Quintanilla \& E. Ticona (eds.) Interculturalidad crítica $y$ descolonización: fundamentos para el debate, (pp. 81-147). La Paz: Convenio Andrés Bello.

Corpus-Flores, A. (2008). Jóvenes tseltales presbiterianos y sus prácticas divergentes: los mensajeros de cristo en la Iglesia Gólgota del Corralito, Oxchuc. Doctoral dissertation, MSc. Thesis, Ciesas, San Cristobal de las Casas, Chiapas, México.

De la Cadena, M. (1992). Las mujeres son más indias. Espejos y Travesías, (16), pp. 25 45 .
Foerster, R. (1986). La Misión Anglicana, primera Iglesia Protestante entre los mapuches. Nütram, II (3), pp. 14-28.

Foerster, R. (1989). Identidad y pentecostalismo indígena en Chile. Creces, 6 (10), pp. 1218.

Garduño, E. (2003). Antropología de la frontera, la migración y los procesos transnacionales. México, D. F.: El Colegio de la Frontera Norte.

Gavilán, V. (2005). Representaciones del cuerpo e identidad de género y étnica en la población indígena del norte de Chile. Estudios Atacameños, (30), pp. 135-148. Doi: $10.4067 / s 0718-10432005000200008$.

González, G. M. (2002). Chilenizando a Tunupa: la escuela pública en el Tarapacá andino 1880-1990. Santiago de Chile: Ediciones de la Dirección de Bibliotecas, Archivos y Museos.

Guerrero, B. (2007). Identidad sociomusical de los jóvenes aymaras: la música sound. Última Década, (27), pp. 11-25. Doi: 10.4067/s0718-22362007000200002.

Gundermann-Kröll, H. (1997). Acerca de cómo los aymara aprendieron el castellano (terminando por olvidar el aymara). Estudios Atacameños, 12, pp. 89-104.

Gundermann-Kröll, H. (2011). Historia moderna de una lengua originaria: el jaqi aru en Chile. RLA. Revista de Lingüistica Teórica y Aplicada, 49 (1), pp. 69-108. Doi: 10.4067/s0718-48832011000100005.

Gundermann-Kröll, H. \& Cortez, H. G. (2008). Pautas de integración regional, migración, movilidad y redes sociales en los pueblos indígenas de Chile. Universum, 23 (1), pp. 82-115. Doi: 10.4067/s071823762008000100006.

Guzmán de Rojas, I. (1985). Problemática lógico-lingüística de la comunicación social con el pueblo de Aymara. Toronto: International Research Development Centre.

Hall, S. (2003). ¿Quién necesita 'identidad'? En S. Hall \& P. du Gay (eds.) Cuestiones de identidad cultural, (pp. 13-39). Buenos Aires: Amorrortu.

Hardman, M. J.; Vásquez, J. \& Yapita, J. de D. (2001). Aymara. Compendio de estructura 
fonológica y gramatical. La Paz: Instituto de Lengua y Cultura Aymara.

Jiménez, A. (2011). Identidad ausente. Del mito de la síntesis a la política de la identificación. Revista Sociedad y Equidad, (2), pp. 3-11. Recuperado de: http://www.sye.uchile.cl/index.php/RSE/ article/view/14710/15063.

Levitt, P. (2007). Rezar por encima de las fronteras: cómo los inmigrantes están cambiando el panorama religioso. Migración y Desarrollo, (8), pp. 66-88.

Magno, L.; Doula, S. M. \& Pinto, N. M. de A. (2011). La formación para el trabajo en la educación media en Colombia. Revista Latinoamericana de Ciencias Sociales, Niñez y Juventud, 9 (1), pp. 305 - 319.

Mansilla, M. Á.; Muñoz, W. \& Orellana, L. (2014). Los dilemas comunitarios y étnicos y religiosos: las investigaciones antropológicas del pentecostalismo aymara y mapuche en Chile (1967-2012). Estudios Atacameños, (49), pp. 153-175. Doi: 10.4067/s0718-10432014000300009.

Mansilla, M. Á. \& Orellana, L. A. (2014). Las pastoras pentecostales: metáforas sobre el liderazgo femenino en la Iglesia Evangélica Pentecostal (1972-2001). Memoria y Sociedad, 18 (36), pp. 83-98. Doi:10.11144/javeriana.mys 18-36.ppml.

Marcús, J. (2011). Apuntes sobre el concepto de identidad. Intersticios. Revista Sociológica de Pensamiento Crítico, 5 (1), pp. 107114.

Marroquín, E. \& Giménez, G. (1996). Los protestantes en Oaxaca: ¿persecusión o resistencia cultural? En G. Giménez (comp.) Identidades religiosas y sociales en México. México, D. F.: Universidad Autónoma de México.

Méndez-Cruz, M. R. (2012). De los habitus al femichismo: reproducción de conductas machistas en mujeres de Cochabamba. Punto Cero, 17 (24), pp. 18-30.

Moulian, R. (2012). Metamorfosis Ritual. Desde el Nguillatun al Culto Pentecostal. Teoría, historia y etnografía del cambio ritual en comunidades mapuche huilliche. Revista Austral de Ciencias Sociales, 22, pp. 131-134. Doi: 10.4206/rev.austral. cienc.soc.2012.n22-09.

Moulian, R.; Oliva, I. \& Toro, S. (2013). Caminar entre luchas y pruebas: funciones paradójicas de la enacción del Espíritu Santo en el culto pentecostal. Chungará (Arica), 45 (3),pp. 461-471. Doi: 10.4067/ s0717-73562013000300007.

Muñoz, W. \& Mansilla, M. Á. (2015). Conflacionismo epistemológico: los estudios sobre el pentecostalismo aymara en Chile (1975-1998). Cinta de Moebio, (52), pp. 1-16. Doi: 10.4067/s0717$554 \times 2015000100001$.

Piñones-Rivera, C.; Mansilla, M. Á. \& Muñoz, W. (2016). "La agarradura me la atiendo en la iglesia": El diablo como símbolo hegemónico en el pluralismo médico aymara pentecostal. Chungará, Revista de Antropología Chilena, 3, pp. 1-11.

Río-Ruiz, M. Á. (2002). Visiones de la etnicidad. Reis, 98 (6), pp. 79-106. Doi:10.2307/40184439.

Stoll, D. \& Barclay, F. (1985). ¿Pescadores de hombres o fundadores de imperio? Lima: Desco.

Vergara, J. I. \& Gundermann-Kröll, H. (2007). El juego de las diferencias: de lo nacionalregional a lo regional-indígena: una comparación entre Tarapacá y Los Lagos. Revista Austral de Ciencias Sociales, 12, pp. 5-34. Doi: 10.4206/rev.austral.cienc. soc.2007.n12-02. 